\title{
The influence of cognitive-perceptual variables on patterns of change over time in rural midlife and older women's healthy eating.
}

\author{
Bernice C, Yates \\ University of Nebraska Medical Center, bcyates@unmc.edu \\ Carol H. Pullen \\ University of Nebraska Medical Center, chpullen@unmc.edu \\ Jonathan Bruce Santo \\ University of Nebraska at Omaha \\ Linda Boeckner \\ University of Nebraska Panhandle Research and Extension Center \\ Patricia A. Hageman \\ University of Nebraska Medical Center, phageman@unmc.edu \\ Tell us how you used this information in this short survey.

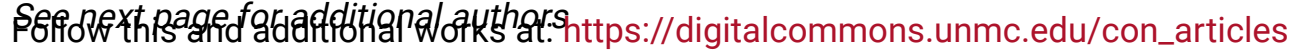 \\ Part of the Nursing Commons
}

\section{Recommended Citation}

Yates, Bernice C; Pullen, Carol H.; Santo, Jonathan Bruce; Boeckner, Linda; Hageman, Patricia A.; Dizona, Paul J.; and Noble Walker, Susan, "The influence of cognitive-perceptual variables on patterns of change over time in rural midlife and older women's healthy eating." (2012). Journal Articles: College of Nursing. 5 . https://digitalcommons.unmc.edu/con_articles/5

This Article is brought to you for free and open access by the College of Nursing at DigitalCommons@UNMC. It has been accepted for inclusion in Journal Articles: College of Nursing by an authorized administrator of DigitalCommons@UNMC.For more information, please contact digitalcommons@unmc.edu. 
Authors

Bernice C, Yates; Carol H. Pullen; Jonathan Bruce Santo; Linda Boeckner; Patricia A. Hageman; Paul J. Dizona; and Susan Noble Walker 


\title{
The Influence of Cognitive-Perceptual Variables on Patterns of Change over Time in Rural Midlife and Older Women's Healthy Eating
}

\author{
Bernice C. Yates, RN, PhD ${ }^{a}$, Carol H. Pullen, EdD, RNa , Jonathan Bruce Santo, PhD $^{\mathrm{b}}$, Linda \\ Boeckner, PhD, RD ${ }^{c}$, Patricia A. Hageman, PhD, PT ${ }^{d}$, Paul J. Dizona, MS ${ }^{a}$, and Susan Noble \\ Walker, EdD, RN, FAAN ${ }^{a}$ \\ aCollege of Nursing, University of Nebraska Medical Center, Omaha \\ bDepartment of Psychology, University of Nebraska at Omaha \\ 'University of Nebraska Panhandle Research and Extension Center, Scottsbluff \\ ${ }^{d}$ Department of Allied Health, University of Nebraska Medical Center, Omaha
}

\begin{abstract}
Although studies demonstrate that dietary interventions for healthy adults can result in beneficial dietary changes, few studies examine when and how people change in response to these interventions, particularly in rural populations. The purpose of this study was to examine patterns of change over time in healthy eating behaviors in midlife and older women in response to a oneyear health-promoting intervention, and to examine what predictors (perceived benefits, barriers, self-efficacy, and family support for healthy eating) influence the changes during the intervention and follow-up. Data for this secondary analysis were from the Wellness for Women communitybased trial. Women $(\mathrm{N}=225)$ between the ages of 50-69 in rural Nebraska, U.S.A., were recruited. A repeated-measures experimental design was used with randomization of two rural counties to intervention (tailored newsletter) or comparison (standard newsletter) groups. Eating behavior was measured by the Healthy Eating Index. The predictor variables were assessed using standard measures. Data analysis was done using latent growth curve modeling. The tailored newsletter group was successful in improving their healthy eating behavior compared to the standard newsletter group during the one-year intervention, at the end of the intervention, and during the follow-up phase. Family support at the end of the intervention was positively associated with healthy eating at the end of the intervention. Perceived barriers had the strongest impact on healthy eating behavior at all time points. Compared to participants in the standard newsletter group, those in the tailored newsletter group perceived more family support and fewer barriers for healthy eating at the end of the intervention (mediation effects). Based on these findings, both family support and perceived barriers should be central components of interventions focused on healthy eating behavior in rural midlife and older women.
\end{abstract}

\section{Keywords}

rural; women; USA; healthy eating; barriers; family support; self-efficacy; benefits

(C) 2012 Elsevier Ltd. All rights reserved.

Corresponding author: Bernice Yates, bcyates@unmc.edu.

Publisher's Disclaimer: This is a PDF file of an unedited manuscript that has been accepted for publication. As a service to our customers we are providing this early version of the manuscript. The manuscript will undergo copyediting, typesetting, and review of the resulting proof before it is published in its final citable form. Please note that during the production process errors may be discovered which could affect the content, and all legal disclaimers that apply to the journal pertain. 
Health promoting interventions are critically important to improve healthy eating and prevent disease in individuals. Studies demonstrate that dietary interventions for healthy adults can result in beneficial dietary changes; however, few studies examined when and how people change in response to these interventions (Brunner et al., 2007; Lin et al., 2010). Fewer studies have examined factors influencing dietary change in rural populations. Thus, the purpose of this secondary analysis was to examine patterns of change over time in healthy eating habits in rural midlife and older women in response to a one-year healthpromoting intervention, and to examine what determinants influence those changes during the intervention and follow-up. The cultural context of this investigation was the rural environment of Nebraska, U.S.A., where the Wellness for Women community-based study was conducted. Of the 93 counties in Nebraska, 85 are considered rural, including 32 counties that are sparsely populated frontier areas. Rural women report poorer health status (Feresu et al., 2008), higher rates of obesity, (Henderson \& Low, 2006), consume higher fat diets (Boeckner et al., 2007), and have lower rates of access to and use of health care services (McCall-Hosenfeld \& Weisman, 2011).

The theoretical approach for this study was a Health Promotion Model (HPM) (Pender et al., 2006) that included four cognitive-perceptual factors as determinants of healthy eating behavior: benefits, barriers, self-efficacy, and family support. All four factors were found to influence dietary behaviors in descriptive studies. Women who perceived greater benefits, self-efficacy, family support and fewer barriers for healthy eating were more likely to consume fruits, vegetables, whole grains, and to limit intake of meat and fats (Walker et al., 2006). Pawlak and Colby (2009) found that perceived benefits of healthy eating generally received higher scores than perceived barriers to healthy eating in African Americans. Kaiser and colleagues (2010) found that rural, low-income individuals who perceived low barriers to healthy eating were significantly more likely to meet the recommended intake for fruits and vegetables. In 4 rural communities in Southwest Georgia, women with greater self-efficacy to eat healthy foods reported less high-fat food in the home and lower levels of dietary fat intake (Hermstad et al., 2010). Similarly, family support was associated with increased fruit and vegetable consumption (Luszczynska \& Cieslak, 2009) and reduced fat intake (Hagler et al., 2007).

Similar to findings from descriptive studies, perceived benefits (Kelley \& Abraham, 2004; Resnicow et al., 2000), barriers (Henson et al., 2010), self-efficacy (Folta et al., 2009; Mosher et al., 2008) and support for healthy eating (Barrera et al., 2008) have all been shown to influence dietary behaviors in intervention studies. Noar and colleagues (2007) conducted a meta-analysis of tailored interventions focused on a wide variety of health behaviors such as smoking cessation, dietary change, and mammography screening. They found that the average effect size (ES) of tailoring on health behavior change was $\mathrm{r}=.074$ (somewhat less than Cohen's small ES of $r=10$ ) suggesting that tailored messages had a greater impact on health behavior than comparison groups. The effect size for tailored interventions on healthy eating behavior was $r=.084$ (Noar et al.). Of the 57 studies reviewed, 44 used a single intervention contact only. In the remaining 13 studies, the number of contacts ranged from 2-12 (median $=3$ ). The most effective interventions were those with $>1$ contact, used pamphlets or newsletters rather than manuals or booklets, and tailored on 4-5 concepts rather than 0-3. Concepts associated with larger effect sizes included attitudes, stages and processes of change, self-efficacy and social support (Noar) of which the latter two are included in this study.

In a recent meta-analysis of the effects of behavioral counseling to promote a healthy diet to prevent cardiovascular disease in adults, Lin et al. (2010) found that interventions significant beyond the first few months in reducing fat and saturated intake and/or increasing fruit and 
vegetable intake were all high-intensity counseling interventions ( $>360$ minutes) with group, phone, or mail contact throughout the trial. Of the 73 studies reviewed, however, only 11 studies followed outcomes beyond 12 months (Lin). In the Wellness for Women study, Walker and colleagues $(2009 ; 2010)$ found that women in the tailored newsletter group, where messages were based on women's individual assessments, made greater improvements in healthy eating (more fruits and vegetables, reduced fat intake) during the 12 month intervention than women in the standard newsletter group (Walker et al., 2009). From 12 to 24 months, however, both groups maintained levels of healthy eating and no group differences were found (Walker et al., 2010). Potential group differences may have been masked by examining separate food categories (intake of fat, fiber, fruits and vegetables) rather than diet as a whole. Thus, in this study, a composite outcome measure of dietary quality was used.

In their seminal work with rural populations, Long and Weinert (1989) found that the culture of rural dwellers centered on the key concepts of work and health beliefs, self-reliance and independence, and isolation and distance. These culturally rooted beliefs and living situations may negatively influence health behaviors. McCall-Hosenfeld and Weisman (2011) compared use of preventive counseling in rural vs. urban women and found that rural women (32\%) were significantly less likely to receive nutrition counseling compared with urban women (40\%). Another study found that rural dwellers do not use preventive services to the same extent as urban dwellers (Pullen et al., 2001). The culture of rural isolation may contribute to altered eating patterns that can challenge women's development of healthy lifestyle patterns (Bove \& Olson, 2006). In many rural areas, the availability of fresh fruits and vegetables is limited in the winter months and grocery stores with these items may be at a distance. Nebraska Behavioral Risk Factor Surveillance System data indicate that only $25.8 \%$ of women eat $\mathbf{\square} 5$ fruits and vegetables daily. Further, fruit and vegetable consumption decreases with increasing age in Nebraska adults (Nebraska Office of Women's and Men's Health Report, 2009-2010).

In summary, although there is consensus that benefits, barriers, self-efficacy, and family support serve as major determinants of healthy lifestyle behavior, there is little consensus about the causal paths linking these variables to behavior. In this study, we want to empirically identify the variables that most strongly influence actual performance of healthy eating behavior. There is a need to establish when and how people change in response to an intervention to focus efforts during the most appropriate time. While theoretical models that describe the determinants and processes of health behavior change are readily available, analyzing these models using latent growth curve modeling will provide insight into how various determinants bring about change in health behavior.

The purpose of this study was to examine patterns of change over time in healthy eating habits in response to a one-year intervention in two treatment groups (tailored and standard newsletter groups); and to examine how determinants influence those changes at each phase of the intervention and follow-up. The specific research questions were:

1) What are the patterns of change during the intervention (baseline, 3, 6, 9, and 12 months) and maintenance period (18 and 24 months) in healthy eating behaviors in response to a oneyear intervention in both tailored and standard newsletter groups? 2) How do the significant determinants (benefits, barriers, self-efficacy, and family support for healthy eating) change during the intervention, and how do they influence changes in healthy eating behavior during and at the end of the intervention and the maintenance period? 3) Which determinants are significant mediators between the tailored vs. standard newsletter groups and healthy eating behavior during and at the end of the intervention and the maintenance period? 


\section{Methods}

The Wellness for Women study was a community-based study using a repeated-measures experimental comparison group design. Women were recruited from two similar rural counties in separate corners of Nebraska. The geographic areas rather than participants were randomized to intervention (tailored newsletters) or comparison (standard newsletter) groups to avoid cross-intervention contamination in these rural areas where women tend to frequent a limited number of commercial and social settings. Although the initial study examined physical activity and eating behaviors; only the eating behaviors are reported here.

\section{Sample}

Two hundred and twenty five women were recruited for the study. Inclusion criteria were: a) women aged 50-69; b) English speaking; and c) able to utilize a computer at rural research offices to complete online surveys. To ensure that all participants would have the potential for change in eating behaviors, women were excluded if they were in the maintenance stage for consumption of fat, fruits and vegetables, and grain intake as measured by the Stages of Healthy Eating Questionnaire (adapted from Marcus et al., 1992). More details about participant recruitment can be found in Walker et al. (2009). The study was approved by the University's Institutional Review Board; each participant provided written informed consent. Although measures included in this study were self-report, all measures were taken by RNs during visits to the rural research office, during the intervention $(0,3,6,9$ and 12 months) and every 6 months during follow-up (18 and 24 months), at which time biomarkers were also assessed. The RNs were blinded to group assignment and were instructed to clarify items on the self-report measures if necessary. They were also specifically instructed to refrain from any type of counseling.

\section{Sample size}

In the original study, power analyses were done for the primary outcomes of changes in eating and activity behavior. Using repeated-measures analysis of variance (RMANOVA), small-to-medium differences were detected in the amount of change between groups (partial $\eta^{2}$ effect size $=.04$ ), alpha $=.05$, and power $\mathbf{\square} 0.80$ (Walker et al., 2009). A larger sample size is typically needed for RMANOVA than for latent growth curve (LGC) analysis because LGC modeling accounts for within subject variability better than RMANOVA; thus, fewer participants are needed (Little, in press).

\section{Theory-based Intervention}

Four behavior-specific cognitions from the HPM shaped the intervention strategies for this study: benefits, barriers, self-efficacy, and interpersonal influences for healthy eating (Bandura, 1997; Pender et al., 2006). These cognitive factors influence behavior directly and are considered modifiable, an essential characteristic of determinants proposed as a basis for structuring interventions to promote health behavior change. The intervention lasted 12 months with an additional 12 month follow-up. Eighteen mailed tailored or standard newsletters were sent to women every 2 weeks for the first 6 months and every 4 weeks for the next 6 months. Both newsletters were written with similar layout, font, and length to minimize differences in appearance. The standard newsletters contained general information about healthy eating that is currently available from organizations such as the American Heart Association and American Cancer Society. For the tailored newsletters, a library of hundreds of messages was created that corresponded to individual women's data. The content of the tailored newsletters was individualized in relation to: Personal goals, most current assessment of benefits, barriers, self-efficacy, and interpersonal support, and biomarker results regarding eating. Of the 18 newsletters, the benefits of healthy eating were discussed in 7, barriers were discussed in 11, self-efficacy was discussed in 16, and 
interpersonal support was discussed in 6 . The daily dietary components emphasized in the intervention were: 2 servings of fruits; 3 servings of vegetables ( 1 dark green or deep yellow); 6 servings of grains ( 3 whole grains); $\mathbf{\square} 30 \%$ of calories from fat; and $<10 \%$ of calories from saturated fat.

\section{Measurement of Predictor Variables}

For the predictor variables in the measurement model, items were selected specifically because they were theoretically relevant and salient to the concept of interest. We then examined their reliability scores using Cronbach's alpha, how well the items factored together, and selected the ones that were the most statistically similar. Once the indicators at each time point were found to be reliable and valid using confirmatory factor analysis, a composite score was created and used as the observed variable for the models.

Perceived benefits and barriers to healthy eating were measured by selected items from the Healthy Eating Benefits and Barriers Scales (HEBBS) (Sechrist et al., 1987). These scales used a 4-point response ranging from 1 (strongly disagree) to 4 (strongly agree). Construct validity, internal consistency, and test-retest reliability were reported by Sechrist et al. (1987). In this study, benefits were measured by 4 items: Healthy eating helps me to be more fit, helps me to have more energy, helps me to lose weight, and makes me feel better. Barriers were measured by 5 items: Healthy eating is inconvenient, too expensive, takes too much time to shop for healthy foods, takes too much time to prepare healthy meals, and means giving up foods that I like. Cronbach alphas for the benefits items ranged from 0.760.84 and for the barriers items ranged from $0.74-0.82$.

Self-efficacy for healthy eating was measured by selected items from the Self-Efficacy for Eating Habits Scale (Sallis et al., 1988). This scale measures individuals' beliefs in their confidence to perform healthy eating behavior under various circumstances. The 6-items were: How confident are you that you would avoid eating fast food for lunch or dinner, eat carrots, celery and raw vegetables instead of dips, crackers, and potato chips for snacks, avoid junk food that other family members have brought into your home, stick to low fat foods when high fat food is readily available at a party, stick to low fat foods when you are alone and there is no one there to watch you, and stick to low fat foods when you feel depressed, bored or tense? Self-efficacy was rated on a 5-point Likert scale ranging from 1 (I know I cannot) to 5 (I know I can). Evidence of construct validity, test-retest reliability, and predictive criterion-related validity were reported (Calfas et al., 1997; Sallis et al., 1988). In this study, Cronbach alphas ranged from 0.81-0.88.

Family support of healthy eating was measured by the Family Support for Healthy Eating Habits Scale (Calfas et al., 1997; Sallis et al., 1987). This scale measures positive encouragement for healthy eating provided by family members. In this analysis, family support for healthy eating was measured by 4 items: My family commented if I went back to my old eating habits, discussed my eating habit changes with me, reminded me not to eat high fat foods, and encouraged me not to eat "unhealthy foods" (for example, cake or fried foods) when I was tempted to do so. Items were measured on a 5-point Likert scale ranging from 1 (none) to 5 (very often) to indicate the frequency of support provided. Higher scores indicated greater family support for healthy eating. The scale has evidence of construct validity, test-retest reliability, and predictive criterion-related validity (Calfas et al., 1997; Sallis et al., 1987). In this study, Cronbach alphas ranged from 0.82-0.86.

\section{Outcome: Healthy Eating Index}

The web-based version of the 1998 Block Health Habits and History Questionnaire was used to measure eating behavior (Boeckner et al., 2002). This food frequency questionnaire 
(FFQ) provides estimates of the nutrients and dietary constituents in a person's diet. The anchors for the FFQ asssessments were: the past year for baseline, past 3 months during the intervention phase, and past 6 months during the maintenance phase. Rather than examine a single food constituent (i.e., fruits and vegetables), we used the Healthy Eating Index (HEI) 2000 (Basiotis et al., 2002) to create a composite score of dietary quality. Typically diet quality indices like the HEI have been calculated from food recalls and records. However, several investigators have successfully calculated and validated HEI scores from FFQs (Boynton et al., 2007; Feskanich et al., 2004; Savoca et al., 2009; Shatenstein et al., 2005) similar to the method used in this study. The HEI measures how well American diets conform to recommended healthy eating patterns and is designed to measure of overall dietary quality. Each of the 10 components (grains, vegetables, fruits, milk, meat, total fat, saturated fat, cholesterol, sodium, and variety) has a scoring range of 0 to 10 . Scores for each component were assigned based on the recommended number of food guide pyramid servings per day for women $\mathbf{\square} 51$ years of age (e.g., a maximum score of 10 points was given for grains $=7.4$ servings, vegetables $=3.5$, fruits $=2.5$, milk $=2$, and meat $=2.2$ ) (Achterberg et al., 1994; Basiotis et al., 2002). In addition, a score of 10 was given for intakes of fat $\mathbf{0} 30 \%$, saturated fat $\mathbf{\square} 10 \%$, cholesterol $\mathbf{\square} 300 \mathrm{mg}$, and sodium $\mathbf{\square} 2400 \mathrm{mg}$. A score of zero was assigned when no foods in a particular group were eaten (or when the following levels were achieved: $45 \%$ fat, $15 \%$ saturated fat, $450 \mathrm{mg}$ cholesterol, and $4800 \mathrm{mg}$ of sodium) (Basiotis et al., 2002). Intermediate scores were calculated proportionately. Variety was calculated by taking 5 food groups (grains, fruits, vegetables, dairy, and meats), counting the number of different foods they had at least a half serving of in a day, and coding on the 0 to 10 scale. The overall HEI has a total possible score ranging from 0 to 100, with 100 indicating best dietary quality. Validity evidence was provided by Hann and colleagues (2001) who found that higher HEI scores were associated with biomarkers of dietary intake.

\section{Data analyses}

Given the longitudinal nature of the data, latent growth curve modeling as recommended by Ram and Grimm (2007), was conducted using M-Plus (M-Plus 6.1, Muthen \& Muthen, 2006). Latent growth curve (LGC) modeling allows us to explain intra-individual change over time by modeling specific trajectories of how this change occurred. The main advantage in LGC modeling is that any number of differing patterns of change can be modeled (Ram \& Grimm, 2007). Then, between-subject differences in change over time can be examined.

First, changes during the intervention were modeled in each of the four predictors (benefits, barriers, self-efficacy, and family support, models 01--04). The criteria for inclusion in later testing were that the variable had to show significant change over the intervention and a significant treatment group effect. Next, models were constructed to examine intraindividual change in healthy eating behavior in response to the intervention in both groups (Models 05-09). These analyses were followed by models to examine between-subject differences in the outcome, in change over time, and what determinants influence those changes at each phase of the intervention and follow-up (Models 10-13). The final analyses aimed to explain whether significant group effects (coded tailored group $=1$ and standard=2) in changes over time in eating behavior were mediated by changes in the predictors (Preacher \& Hayes, 2004). The significance level for the study was set at .05. The amount of missing data in the Healthy Eating Index at each time point $(0,3,6,9,12,18$, and 24 months) was: $0 \%, 2 \%, 5 \%, 7 \%, 5 \%, 6 \%$, and 5\%, respectively. M-Plus uses FIML (full information maximum likelihood) to impute missing data. 


\section{Results}

Women in both groups were, on average, 58 years old ( $\mathrm{SD}=5.5$; Range $=50-69)$, Caucasian, married, employed outside the home, had attended some college or were college graduates, had an average BMI of 30 which did not change over time, and reported annual incomes > $\$ 20,000$ (Walker et al., 2009). Summary scores for each predictor variable were calculated by group (Table 1$)$.

\section{Change over time in predictors}

A separate latent growth curve model was created for each predictor testing for differences during the intervention. Model fit statistics are provided in Table 2. For self-efficacy and benefits for healthy eating, no significant change over time or any significant differences between groups were observed. For family support, a significant increase over the first year of the intervention was observed ( $b=.160, \beta=.599, \mathrm{z}=2.82, \mathrm{p}<.05)$. At the end of the intervention, the tailored newsletter group reported significantly more family support than the standard newsletter group $(b=-.289, \beta=-.366, \mathrm{z}=2.40, \mathrm{p}<.05)$. For perceived barriers, a significant decrease was observed during the intervention $(b=-.101, \beta=-.455, z=3.34, p<$. $05)$ and the tailored group reported significantly fewer barriers than the standard group $(b=$. $140, \beta=.369, z=2.42, p<.05)$ at the end of the intervention. Based on these results, only family support and barriers were used in later testing of changes over time in healthy eating.

\section{Intra-individual change}

Next, change over time in healthy eating behavior was examined (Figure 1). We tested an unconditional model (Model 05, Table 2) which served as a basis for comparison in the model building process. Model 06 examined simple linear change over time (whether healthy eating improved over all 7 time points; Figure 2). Model 07 tested a revised linear model to separate change during the intervention from change during the maintenance period. The linear models proved a poor fit to the data. Model 08 examined curvilinear change over time ( 7 time points) and Model 09 separated change during the intervention from change during follow-up. This last model represented the best statistical and theoretical fit to the data.

\section{Inter-individual differences}

Next, we examined whether groups differed in healthy eating change as a result of the intervention, at the end of the intervention, and during follow-up. Model 10 reflects the addition of treatment group to the model (Figure 3). The tailored newsletter group increased healthy eating more than the standard newsletter group $(b=-6.661, \beta=-.452, z(1-$ tailed) $=1.73, p<.05)$. Statistically significant differences were observed at the end of the intervention $(b=-7.199, \beta=-.705, z=4.93, p<.05)$ and in maintenance $(b=-7.245, \beta=-.721$, $\mathrm{z}=5.12, \mathrm{p}<.05)$. No significant group difference was observed in the curvilinear effects $(b=$ $-1.832, \beta=-.114, \mathrm{z}=.482, \mathrm{p}>.05)$.

Model 11 reflects the addition of barriers to the model. Decreases in barriers during the intervention were significantly related to increases in healthy eating over this same time frame $(b=-47.438, \beta=-.643, \mathrm{z}(1$-tailed $)=1.66, \mathrm{p}<.05)$. Lower barriers at the end of the intervention were related to better healthy eating scores at the end of the intervention $(b=$ $-7.286, \beta=-.269, \mathrm{z}=3.08, \mathrm{p}<.05)$ and resulted in higher HEI scores during the maintenance period $(b=-10.775, \beta=-.410, z=5.16, p<.05)$.

Model 12 reflects the addition of family support. Healthy eating at the end of the intervention was positively associated with family support at the end of the intervention $(b=1.500, \beta=.116, z=2.39, p<.05)$. No significant effects were observed for change over time 
in family support on changes in the HEI outcomes. Separate post-hoc analyses revealed a significant association between healthy eating during the second year and family support at the same time ( $b=2.086, \beta=.211, \mathrm{z}=2.45, \mathrm{p}<.05)$. Lastly, analyses for latent moderation were done to test whether the effect of barriers on healthy eating differed as a function of differing levels of family support. No significant interactions were observed suggesting that the effects in the current analyses were independent of each other.

\section{Tests for Mediation}

The final set of analyses examined whether the observed group differences in healthy eating were mediated by the group effects on family support and perceived barriers (Model 13). Part of the treatment group effect on healthy eating at the end of the intervention was through a decrease in barriers $(\mathrm{b}=-1.003, \beta=-.098, \mathrm{z}=2.07, \mathrm{p}<.05)$ and an increase in family support $(b=-.420, \beta=-.041, \mathrm{z}(1$-tailed $)=1.74, \mathrm{p}<.05)$ reflecting a $19.43 \%$ drop in the standardized coefficient. Finally, part of the group effect on healthy eating during maintenance was also through a decrease in barriers by the end of the intervention $(b=1.384$, $\beta=-.139, \mathrm{z}=2.23, \mathrm{p}<.05$ ) reflecting a $19.56 \%$ drop in the standardized coefficient.

\section{Discussion}

Healthy eating as measured by the HEI increased in both groups with the majority of change occurring in the first six months. The tailored newsletter group increased their healthy eating more than the standard newsletter group during and at the end of the intervention, and during follow-up. It is worth noting that no significant group difference was observed in the curvilinear effects suggesting that both groups decreased similarly after making initial gains. Although healthy eating scores dropped for both groups after 6 months, the tailored newsletter group maintained their healthy eating behavior at a significantly higher level than the standard newsletter group. This latter group dropped below their baseline score $(\mathrm{M}=69.5)$ at month 9 and remained below baseline throughout the 24 month follow-up. In the evaluation of the study, women mentioned that they learned how to be more accurate at completing the food frequency questionnaire during the study, which may explain why scores dropped in both groups after 6 months. Future studies could potentially train participants in accurate reporting of eating habits before starting an intervention.

Using a composite measure of eating behavior may have captured the robust differences between groups in eating behavior better than single food categories (i.e., fruits \& vegetables). In several studies, the mean HEI for women of varying ages was as low as 42.8 for low-income women, ages 19-50 (Duffy et al., 2009); but typically was in the 60s for women ages 51 and older (Boynton et al., 2007; Grimstvedt et al., 2009; Savoca et al., 2009; Tande et al., 2009). This would place most midlife to older women in a fair/good classification for healthy eating according to this index. The HEI results for the women in our study were slightly above earlier results.

It appears that providing rural women with tailored messages had a greater influence on patterns of change in healthy eating behavior than the standard newsletters. From prior studies, tailored interventions typically have longer lasting and more powerful effects than standard newsletters (Noar et al., 2007). In this study, the tailored group was able to sustain their eating behavior changes better than the standard group in part because of the individualized information they received. Although prior literature has found that rural dwellers do not use preventive services to the same extent as their counterparts (Bove \& Olson, 2006; McCall-Hosenfeld \& Weisman, 2011; Paluck et al., 2006; Pullen et al., 2001), it is likely that the individualized counseling about lifestyle behavior delivered via an easily accessible method that could be reviewed at their convenience were key factors in bringing about the change. 
Three significant effects were observed for the influence of family support. First, family support at the end of the intervention was positively associated with healthy eating at this same time point. Second, family support during the follow-up year was also related to healthy eating during follow-up. Third, during the intervention, family support increased more in the tailored newsletter group than the standard newsletter group. Women in this group were able to garner more family support as a direct result of the tailored intervention which, in turn, was related to healthier eating for them at the end of the intervention. The six newsletters that were devoted to interpersonal support covered such topics as how to ask for support for healthy eating, accepting help that is provided, ideas about who to ask for support, and so forth. In earlier studies, more family support was related to higher levels of healthy eating in women (Chang et al., 2005; Luszczynska \& Cieslak, 2009; Steptoe et al., 2004). The current findings support the cultural belief that rural women rely on their families for assistance with health-promoting behaviors (Long \& Weinert, 1989; Paluck et al., 2006). In contrast, two studies found that family support for nutrition was related to healthier eating but this effect was, in large part, indirect through other predictors (Anderson et al., 2007; Luszczynska \& Cieslak, 2009). Similarly, Hermstad and colleagues (2010) did not find a relationship between family support for healthy eating and dietary fat intake in their study of rural men and women. The role of family support for healthy eating warrants further study.

It was surprising that self-efficacy for healthy eating did not differ between the treatment groups and was not related to healthy eating behavior in the current study. Although earlier investigators also have not found a significant relationship between these variables (Brug et al., 2006; Kellar \& Abraham, 2005), self-efficacy, more than any other determinant, has been related to healthy eating behavior (Anderson et al., 2007; Folta et al., 2009; Fuemmeler et al., 2006; Luszczynska \& Cieslak, 2009). In this study, self-efficacy for healthy eating was the strategy given the most emphasis, discussed in 16 of 18 newsletters. Despite this emphasis, the mean scores for self-efficacy were fairly high in both groups and remained stable over time. This suggests that there may have been a ceiling effect for self-efficacy such that both groups already had a "threshold" level of self-efficacy and other psychosocial factors were more salient. Alternatively, it may be that increasing the women's confidence for healthy eating may have required a stronger, more intense intervention than a mailed newsletter (Lin et al., 2010).

Several effects were observed for the influence of perceived barriers. First, decreases in barriers over the intervention were related to increases in healthy eating over this same time. Second, lower barriers at the end of the intervention were related to better healthy eating scores at the end of the intervention. Third, lower barriers at the end of the intervention resulted in higher healthy eating scores during maintenance. In addition, participants in the tailored newsletter group perceived fewer barriers to healthy eating than those in the standard newsletter group at the end of the intervention and during the maintenance phase, which resulted in healthier eating. It appears that the tailored newsletters were effective in counteracting many of the barriers that women perceived during the intervention (inconvenience, expense, time required for shopping and preparing healthy meals, and giving up preferred foods). Similar to this study, several earlier studies found that barriers were negatively related to healthy eating behavior (Brug et al., 2006; Kaiser et al., 2010). In focus group participants, Rolnick et al. (2009) reported that barriers to fruit and vegetable consumption were lack of time, expense, and fruit and vegetable availability.

Perceived benefits of healthy eating did not differ between the treatment groups or related to healthy eating behavior in this study. Benefits of healthy eating have not shown as consistent an effect on eating behavior in prior research as other determinants (Shaikh et al., 2008). Compared to self-efficacy or social support, it may be that the benefits of eating healthy 
foods are too distant in time to have a strong influence on the women's eating behavior as suggested by Hagler et al. (2007).

This study has several limitations. The composite outcome used in the current analysis (HEI instead of separate food categories), made this analysis difficult to compare with the earlier published results from this study. A further limitation was the varying time frame for measuring the food frequency questionnaire from every three months during the intervention, to every six months during maintenance, and the past year at baseline. Although the women's BMI did not change over time, future studies should examine the effects of changes in eating behavior on BMI. Data were based on self-report and women may not have recalled eating behaviors accurately. Although we used cluster randomization to assign the two rural counties to intervention groups, we were unable to take into account the effect of clustering because we only had one cluster (county) per group. Future studies need to account for effects of clustering. Because we were not able to collect baseline data on nonparticipants, it was unknown how they differed from participants. Women generally lived within 50 miles of the rural research office and thus had fewer barriers to travel compared to other rural women. Thus, the generalizability of the findings is limited to midlife/older women who reside in rural areas similar to this study. More research is needed to clarify the effects of self-efficacy and benefits on healthy eating behavior in rural women as these were not significant in this study.

In summary, the tailored newsletter intervention was successful in improving participants' healthy eating behavior compared to the standard newsletter intervention during and at the end of the intervention, and during maintenance. Perceived barriers had the strongest impact on healthy eating behavior during and at the end of the intervention and the maintenance period. Participants in the tailored newsletter group perceived more family support and fewer barriers for healthy eating at the end of the intervention than those in the standard newsletter group. Thus, both family support and barriers should be a major focus of interventions to improve healthy eating behavior in rural midlife and older women.

\section{Acknowledgments}

This research was supported by Grant R01 NR04861 and Grant P20 NR011404 from the National Institute of Nursing Research, National Institute of Health and by the University of Nebraska Medical Center Clinical Research Center, Research Support Fund.

\section{References}

Achterberg C, McDonnell E, Bagby R. How to put the food guide pyramid into practice. Journal of the American Dietetic Association. 1994; 94(9):1030-1035. [PubMed: 8071485]

Anderson ES, Winett RA, Wojcik JR. Self-regulation, self-efficacy, outcome expectations, and social support: Social cognitive theory and nutrition behavior. Annals of Behavioral Medicine. 2007; 34(3):304-312. [PubMed: 18020940]

Bandura, A. Self-Efficacy: The Exercise of Control. New York: W.H. Freeman \& Company; 1997.

Barrera M Jr, Strycker LA, MacKinnon DP, Toobert DJ. Social-ecological resources as mediators of two-year diet and physical activity outcomes in Type 2 diabetes patients. Health Psychology. 2008; 27(2 Suppl):S118-S125. [PubMed: 18377153]

Basiotis, PP.; Carlson, A.; Gerrior, SA.; Juan, WY.; Lino, M. The Healthy Eating Index: 1999-2000. U.S. Department of Agriculture, Center for Nutrition Policy and Promotion; 2002. CNPP-12

Boeckner L, Pullen CH, Walker SN, Oberdorfer MK, Hageman PA. Eating behaviors and health history of rural midlife to older women in Midwestern United States. Journal of American Dietetic Association. 2007; 107(2):306-310. 
Boeckner L, Pullen CH, Walker SN, Abbot G, Block T. Use and reliability of the world wide web version of the Block Health Habits and History questionnaire with older rural women. Journal Nutrition Education Behavior. 2002; 34(S1):S20-S24.

Bove CF, Olson CM. Obesity in low-income rural women: Qualitative insights about physical activity and eating patterns. Women \& Health. 2006; 44(1):57-78.

Boynton A, Neuhouser ML, Wener MH, Wood B, Sorensen B, Chen-Levy Z, et al. Associations between healthy eating patterns and immune function or inflammation in overweight or obese postmenopausal women. American Journal of Clinical Nutrition. 2007; 86:1445-1455. [PubMed: 17991658]

Brug J, de Vet E, de Nooijer J, Verplanken B. Predicting fruit consumption: Cognitions, intention, and habits. Journal of Nutrition Education and Behavior. 2006; 38:73-81. [PubMed: 16595285]

Brunner E, Rees K, Ward K, Burke M, Thorogood M. Dietary advice for reducing cardiovascular risk. Cochrane Database of Systematic Reviews. 2007:4.

Calfas K, Sallis J, Oldenburg B, Ffrench M. Mediators of change in physical activity following an intervention in primary care: PACE. Preventive Medicine. 1997; 26(3):297-304. [PubMed: 9144753]

Chang M, Baumann LD, Nitzke S, Brown RL. Predictors of fat intake behaviors differ between normal-weight and obese WIC mothers. American Journal of Health Promotion. 2005; 19:269_ 277. [PubMed: 15768921]

Duffy P, Zizza C, Jacoby J, Tayie FA. Diet quality is low among female food pantry clients in eastern Alabama. Journal of Nutrition Education and Behavior. 2009; 41(6):414-419. [PubMed: 19879497]

Feresu SA, Zhang W, Puumala SE, Ullrich F, Anderson JR. The frequency and distribution of cardiovascular disease risk factors among Nebraska women enrolled in the WISEWOMAN screening program. Journal of Women's Health. 2008; 17(4):607-617.

Feskanich D, Rockett HRH, Colditz GA. Modifying the Heathy Eating Index to assess diet quality in children and adolescents. Journal of the American Dietetic Association. 2004; 104:1375-1383. [PubMed: 15354153]

Folta SC, Lichtenstein AH, Seguin RA, Goldberg JP, Kuder JF, Nelson ME. The Strong WomenHealthy Hearts Program: Reducing cardiovascular disease risk factors in rural sedentary, overweight, and obese midlife and older women. American Journal of Public Health. 2009; 99(7): 1271-1277. [PubMed: 19443826]

Fuemmeler BF, Mâsse LC, Yaroch AL, Resnicow K, Campbell MK, Carr C, et al. Psychosocial mediation of fruit and vegetable consumption in the body and soul effectiveness trial. Health Psychology. 2006; 25(4):474-483. [PubMed: 16846322]

Grimstvedt ME, Woolf K, Milliron BJ, Manore MM. Lower Health Eating Index-2005 dietary quality scores in older women with rheumatoid arthritis v. healthy controls. Public Health Nutrition. 2009; 13(8):1170-1177. [PubMed: 20188003]

Hann CS, Rock CL, King I, Drewnowski A. Validation of the Healthy Eating Index with use of plasma biomarkers in a clinical sample of women. American Journal of Clinical Nutrition. 2001; 74:479486. [PubMed: 11566646]

Henderson J, Low S. Obesity: America's economic epidemic. Center for the Study of Rural America. 2006; 1(2):1-4.

Henson S, Blandon J, Cranfield J. Difficulty of healthy eating: A Rasch model approach. Social Science \& Medicine. 2010; 70:1574-1580. [PubMed: 20219277]

Hermstad AK, Swan DW, Kegler MC, Barnette JK, Glanz K. Individual and environmental correlates of dietary fat intake in rural communities: A structural equation model analysis. Social Science \& Medicine. 2010; 71:93-101. [PubMed: 20462682]

Hagler AS, Norman GJ, Zabinski MF, Sallis JF, Calfas KJ, Patrick K. Psychosocial correlates of dietary intake among overweight and obese men. American Journal of Health Behavior. 2007; 31(1):3-12. [PubMed: 17181457]

Kaiser BL, Brown RL, Baumann LC. Perceived influences on physical activity and diet in low-income adults from two rural counties. Nursing Research. 2010; 59(1):67-75. [PubMed: 20010047] 
Kellar I, Abraham C. Randomized controlled trial of a brief research-based intervention promoting fruit and vegetable consumption. British Journal of Health Psychology. 2005; 10:543-558. [PubMed: 16238864]

Kelley K, Abraham C. RCT of a theory-based intervention promoting healthy eating and physical activity amongst out-patients older than 65 years. Social Science \& Medicine. 2004; 59(4):787797. [PubMed: 15177835]

Lin JS, O'Connor E, Whitlock EP, Beil TL. Behavioral counseling to promote physical activity and a healthful diet to prevent cardiovascular disease in adults: A systematic review for the U.S. preventive services task force. Annals of Internal Medicine. 2010; 153:736-750. [PubMed: 21135297]

Little, TD. Longitudinal structural equation modeling. New York: Guilford Press; (in press)

Long KA, Weinert C. Rural nursing: Developing the theory base. Scholarly Inquiry for Nursing Practice. 1989; 3(2):113-125. [PubMed: 2772454]

Luszczynska A, Cieslak R. Mediated effects of social support for healthy nutrition: Fruit and vegetable intake across 8 months after myocardial infarction. Behavioral Medicine. 2009; 35:30-37. [PubMed: 19297302]

Marcus BH, Rossi J, Selby V, Niaura RS, Abrams D. The stages and processes of exercise adoption and maintenance in a worksite sample. Health Psychology. 1992; 11:386-395. [PubMed: 1286658]

McCall-Hosenfeld JS, Weisman CS. Receipt of preventive counseling among reproductive-aged women in rural and urban communities. Rural and Remote Health. 2011; 11:1617. (Online). Available from: http://www.rrh.org.au. [PubMed: 21280972]

Mosher CE, Fuemmeler BF, Sloane R, Kraus WE, Lobach DF, Snyder DC, Demark-Wahnefried W. Change in self-efficacy partially mediates the effects of the FRESH START intervention on cancer survivors' dietary outcomes. Psycho-Oncology. 2008; 17:1014-1023. [PubMed: 18300337]

Muthén, LK.; Muthén, BO. Mplus: Statistical Analysis with Latent Variables. 4. Los Angeles, CA: Muthén \& Muthén; 2006.

Nebraska Office of Women's and Men's Health Report. 2009-2010. http://www.hhss.ne.gov/hew/ OWH/docs/Annual_Reports/2010.pdf, Retrieved, February 12011

Noar SM, Benac CN, Harris MS. Does tailoring matter? Meta-analytic review of tailored print health behavior change interventions. Psychological Bulletin. 2007; 133(4):673-693. [PubMed: 17592961]

Paluck EC, Allerdings M, Kealy K, Dorgan H. Health promotion needs of women living in rural areas: An exploratory study. Canadian Journal of Rural Medicine. 2006; 11(2):111-116. [PubMed: 16630437]

Pawlak R, Colby S. Benefits, barriers, self-efficacy and knowledge regarding healthy foods; perception of African Americans living in eastern North Carolina. Nutrition Research and Practice. 2009; 3(1):56-63. [PubMed: 20016703]

Pender, N.; Murdaugh, C.; Parsons, M. Health Promotion in Nursing Practice. 5. Upper Saddle River, New Jersey: Prentice Hall; 2006.

Preacher KJ, Hayes AF. SPSS and SAS procedures for estimating indirect effects in simple mediation models. Behavior Research Methods, Instruments, \& Computers. 2004; 36(4):717-731.

Pullen C, Fiandt K, Walker SN. Determinants of preventive services utilization in rural older women. Journal of Gerontological Nursing. 2001; 27(1):40-51. [PubMed: 11915096]

Ram N, Grimm K. Using simple and complex growth models to articulate developmental change: Matching theory to method. International Journal of Behavioral Development. 2007; 31(4):303316.

Resnicow K, Wallace DC, Jackson A, Digirolamo A, Odom E, Wang T, et al. Dietary change through African American churches: Baseline results and program description of the eat for life trial. Journal of Cancer Education. 2000; 15(3):156-163. [PubMed: 11019764]

Rolnick SJ, Calvi J, Heimendinger J, McClure JB, Kelley M, Johnson C, Alexander GL. Focus groups inform a web-based program to increase fruit and vegetable intake. Patient Education and Counseling. 2009; 77:314-318. [PubMed: 19409750] 
Sallis JF, Grossman RM, Pinski RB, Patterson TL, Nader PR. The development of scales to measure social support for diet and exercise behaviors. Preventive Medicine. 1987; 16(6):825-836. [PubMed: 3432232]

Sallis JF, Pinski RB, Grossman RM, Patterson TL, Nader PR. The development of self-efficacy scales for health-related diet and exercise behaviors. Health Education Research: Theory \& Practice. 1988; 3(3):282-292.

Savoca MR, Arcury TA, Leng X, Bell RA, Chen H, Anderson AS, et al. The diet quality of rural older adults in the South as measured by Healthy Eating Index-2005 varies by ethnicity. Journal of the American Dietetic Association. 2009; 109:2063-2067. [PubMed: 19942025]

Sechrist KR, Walker SN, Pender NJ. Development and psychometric evaluation of the Exercise Benefits/Barriers Scale. Research in Nursing \& Health. 1987; 10(6):357-365. [PubMed: 3423307]

Shaikh AR, Yaroch AL, Nebeling L, Ming-Chin Y, Resnicow K. Psychosocial predictors of fruit and vegetable consumption in adults: A review of the literature. American Journal of Preventive Medicine. 2008; 34(6):535-543. [PubMed: 18471592]

Shatenstein B, Nadon S, Godin C, Ferland G. Diet quality of Montreal-area adults needs improvement: Estimates from a self-administered food frequency questionnaire furnishing a dietary indicator score. Journal of the American Dietetic Association. 2005; 105:1251-1260. [PubMed: 16182642]

Steptoe A, Perkins-Porras L, Rink E, Hilton S, Cappuccio FP. Psychological and social predictors of changes in fruit and vegetable consumption over 12 months following behavioral and nutrition education counseling. Health Psychology. 2004; 23(6):574-581. [PubMed: 15546225]

Tande DL, Magel R, Strand BN. Healthy Eating Index and abdominal obesity. Public Health Nutrition. 2009; 13(2):208-214. [PubMed: 19650960]

Walker SN, Pullen C, Hertzog M, Boeckner L, Hageman PA. Determinants of older rural women's activity and eating. Western Journal of Nursing Research. 2006; 28(4):449-468. [PubMed: 16672632]

Walker SN, Pullen CH, Boeckner L, Hageman PA, Hertzog M, Oberdorfer MK, Rutledge MJ. Clinical trial of tailored activity and eating newsletters with older rural women. Nursing Research. 2009; 58(2):74-85. [PubMed: 19289928]

Walker SN, Pullen CH, Hageman PA, Boeckner LS, Hertzog M, Oberdorfer MK, Rutledge MJ. Maintenance of activity and eating change after a clinical trial of tailored newsletters with older rural women. Nursing Research. 2010; 59(5):311-321. [PubMed: 20697307] 
- Reducing barriers to healthy eating via the tailored newsletters was the primary factor that improved eating behavior.

- The tailored newsletters also helped women in this group garner more family support which was related to healthier eating.

- Key components of healthy eating interventions in rural older women should focus on family support and perceived barriers.

- Findings support the cultural belief that rural women rely on their families to assist with health-promoting behaviors. 


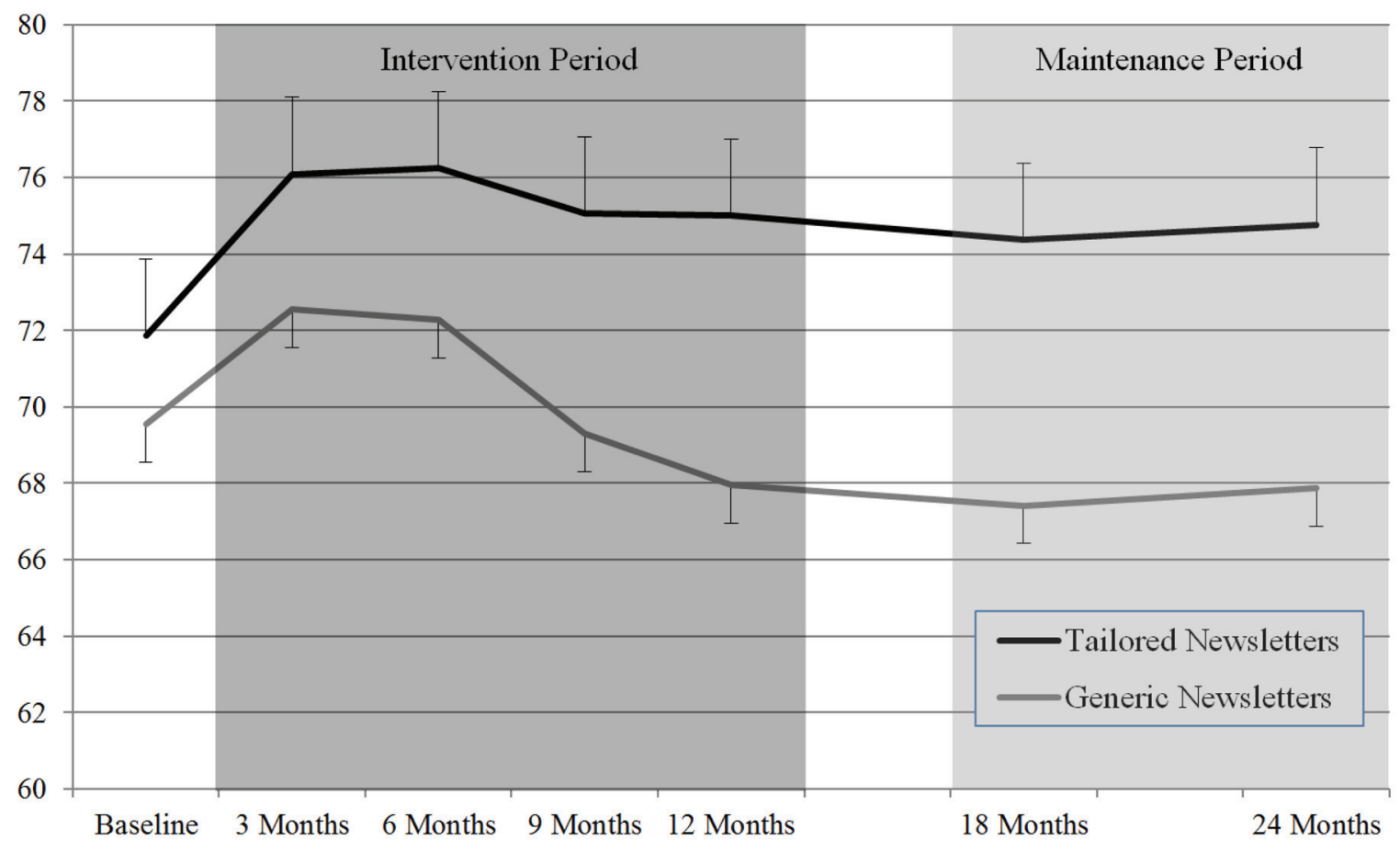

Figure 1. Raw Mean Values of the Healthy Eating Index by Group during the Intervention (3 to 12 months) and Maintenance (18 and 24 months) Periods (with Standard Errors) Legend: The darker shading represents the intervention period and the lighter shading represents the maintenance period. 

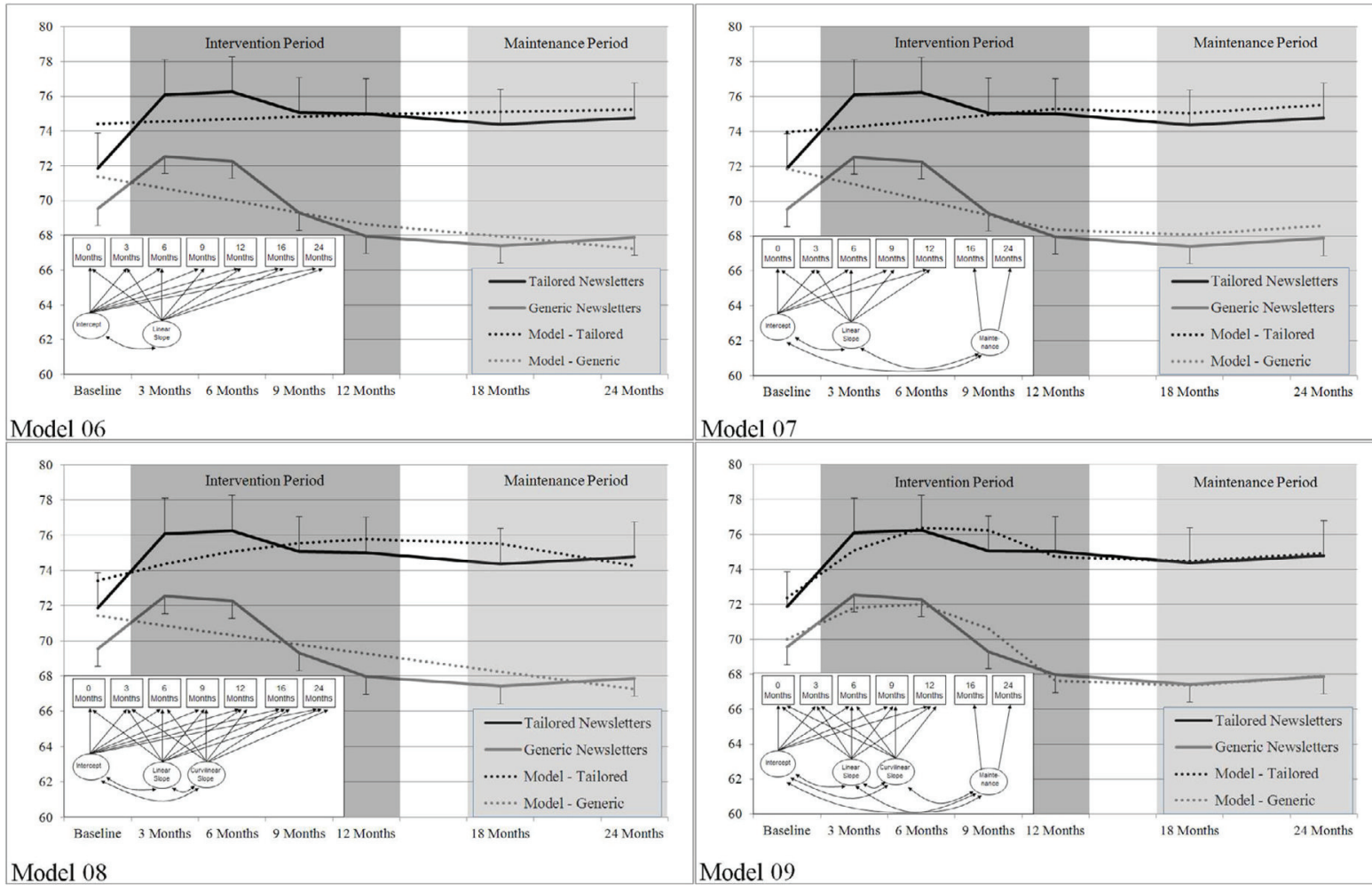

Model 07

Figure 2. Fitted lines plotted against the mean scores of the Healthy Eating Index (HEI) at each time point

The solid lines denote raw mean scores. The dotted lines denote fitted scores.

Model 06 examined simple linear change over time using all 7 time points; model 07 was a revised linear model separating change during the intervention from change during maintenance. Model 08 examined curvilinear change over time using all 7 time points; model 09 was a revised curvilinear model separating change during the intervention from change during maintenance (best statistical and theoretical fit to the data). HEI Intercept was rescaled to represent healthy eating at the end of the intervention. HEI Linear denotes the intra-individual linear change over time. HEI Curvilinear denotes the intra-individual curvilinear change over time. HEI Maintenance denotes healthy eating index scores during the maintenance period. 

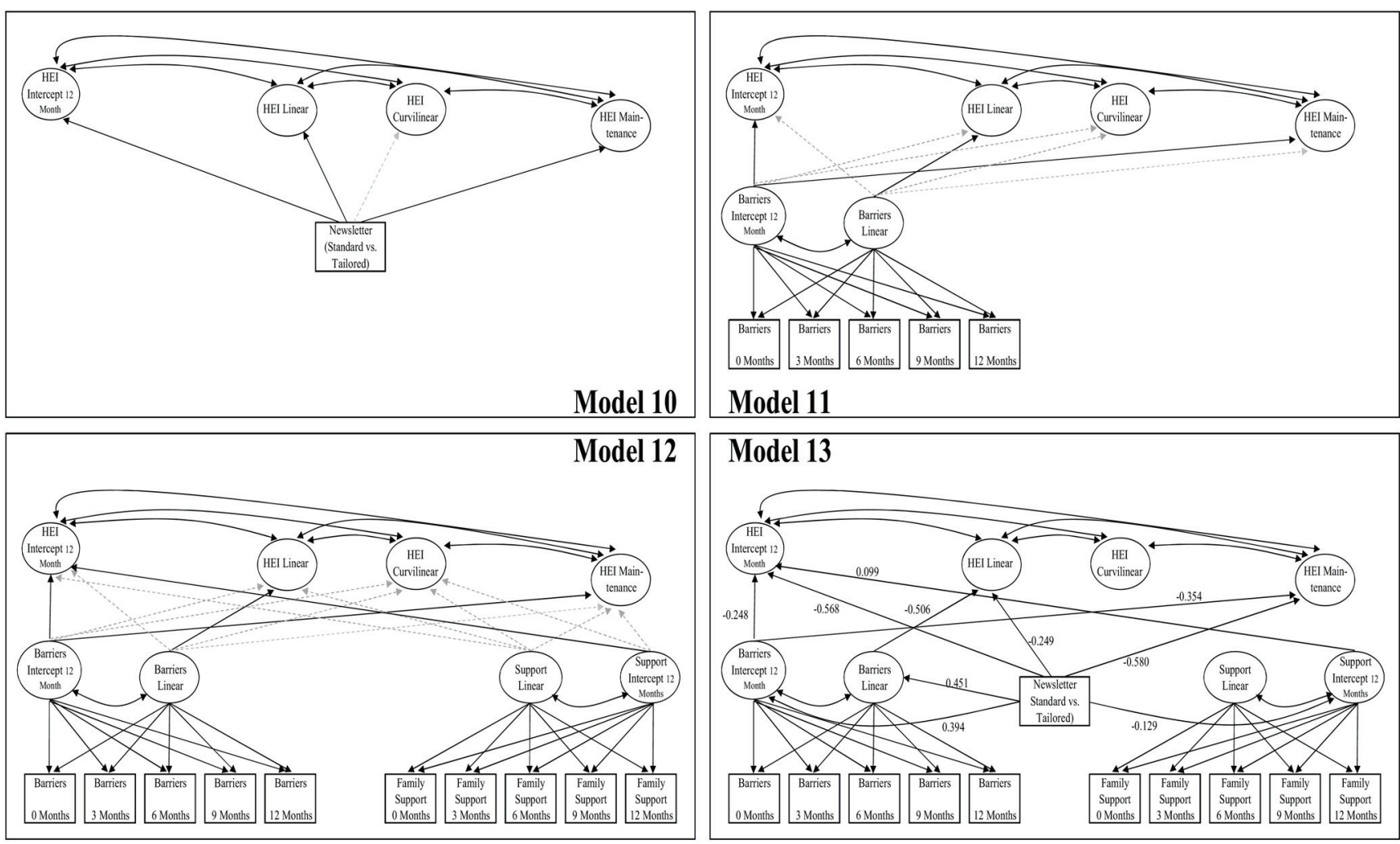

Figure 3. Model Building Process for Explaining Change over Time in Rural Midlife and Older Women's Healthy Eating Behavior

Note. Standardized beta coefficients are provided for the significant values in Models 10 \& 11; Models 12 \& 13 were included to depict model construction. In Model 13, variance explained is by each latent construct.

HEI = Healthy Eating Index (The indicators of healthy eating for the 7 assessments have been removed for clarity.)

Intercept was rescaled to represent healthy eating at the end of the intervention for HEI, barriers, and family support.

Linear denotes the intra-individual linear change over time.

Curvilinear denotes the intra-individual curvilinear change over time.

HEI maintenance: denotes the healthy eating index score during the maintenance period 
Table 2

\section{Summary of Model Fit Statistics}

\begin{tabular}{|c|c|c|c|c|}
\hline Model Details & $\chi^{2}(\mathrm{df})$ & CFI & RMSEA & SRMR \\
\hline \multicolumn{5}{|l|}{ Changes in the Predictors } \\
\hline 01 Self-efficacy for healthy eating & $14.60(13)$ & .99 & .02 & .03 \\
\hline 02 Benefits & $6.68(13)$ & 1.00 & .00 & .04 \\
\hline 03 Family support & $17.88(13)$ & .99 & .05 & .06 \\
\hline 04 Perceived barriers & $12.89(13)$ & .99 & .04 & .09 \\
\hline \multicolumn{5}{|l|}{ Intra-Individual Models } \\
\hline 05 Unconditional Model & $1100.70(21)^{*}$ & N/A & .48 & .51 \\
\hline 06 Linear Change & $106.47(23)^{*}$ & .92 & .13 & .11 \\
\hline 07 Revised Linear Model & $30.55(14)^{*}$ & .98 & .07 & .07 \\
\hline 08 Curvilinear Change & $82.59(19)^{*}$ & .94 & .12 & .06 \\
\hline 09 Revised curvilinear model & $18.70(10)$ & .99 & .06 & .03 \\
\hline \multicolumn{5}{|l|}{ Inter-Individual Models } \\
\hline 10 Main effects of newsletter & $19.28(13)$ & .99 & .05 & .03 \\
\hline 11 Barriers for healthy eating & $80.73(44) *$ & .98 & .06 & .06 \\
\hline 12 Family support & $147.84(110)^{*}$ & .98 & .04 & .06 \\
\hline 13 Mediational Model & $157.02(124) *$ & .99 & .03 & .06 \\
\hline \multicolumn{5}{|l|}{$*$} \\
\hline \multicolumn{5}{|l|}{ Note. N/A = Not applicable } \\
\hline \multicolumn{5}{|l|}{$\mathrm{CFI}=$ Comparative Fit Index } \\
\hline RMSEA = Root Mean Square Error c & Approximation & & & \\
\hline
\end{tabular}

